\title{
Impact of endemic HIV on emergency care service delivery in South Africa
}

\author{
E A Hahn, ${ }^{1}$ BS; G Mwinnyaa, ${ }^{1,2}$ MHS; A Rao, ${ }^{1}$ MSPH; L Wallis, ${ }^{3}$ MB BCh; J Black, ${ }^{4}$ MB BCh; R Maharaj, ${ }^{5}$ MB BCh; \\ A Pousson, ${ }^{6} \mathrm{MD}, \mathrm{MPH}$; S J Reynolds, ${ }^{1,6} \mathrm{MD}$, MPH; T C Quinn, ${ }^{2,6} \mathrm{MD}, \mathrm{MSc}$; B Hansoti, ${ }^{6} \mathrm{MB}$ BCh, MPH, PhD \\ ${ }^{1}$ Johns Hopkins Bloomberg School of Public Health, Baltimore, Md., USA \\ ${ }^{2}$ Division of Intramural Research, National Institute of Allergy and Infectious Diseases, National Institutes of Health, Bethesda, Md., USA \\ ${ }^{3}$ Division of Emergency Medicine, Faculty of Health Sciences, University of Cape Town, South Africa \\ ${ }^{4}$ Department of Infectious Disease, Livingstone Hospital, Port Elizabeth, South Africa \\ ${ }^{5}$ Department of Emergency Medicine, Livingstone Hospital, Port Elizabeth, South Africa \\ ${ }^{6}$ Johns Hopkins School of Medicine, Baltimore, Md., USA
}

Corresponding author: E A Hahn (ehahn6@jhmi.edu)

\begin{abstract}
Background. South Africa (SA) has the highest burden of HIV in the world. This study sought to evaluate the impact of high HIV prevalence on the burden of disease in an emergency department (ED).

Objectives. To determine the burden of comorbidities in HIV-positive emergency care patients, their demographic profiles and severity of illness were compared with the general ED population in order to make recommendations for resource allocation and training in EDs in SA. Methods. A prospective cross-sectional observational study was conducted from June 2017 to July 2018 in three EDs in Eastern Cape Province. All eligible patients (aged $\geq 18$ years, fully conscious and clinically stable) presenting to the ED during the 6-week study period were approached and asked to give consent for a point-of-care HIV test and collection of demographic information. Simple descriptive statistics were used to analyse data. Log binomial and Poisson models were fitted to estimate prevalence ratios (PRs).

Results. Over the total study period, 8000 patients presented to the ED for care across all sites and 3537 patients were enrolled. The HIV status of 2901 individuals (82.0\%) was determined. Of those who were screened, 811 (28.0\%) were identified as HIV-positive. Medical complaints were more common in HIV-positive patients $(n=586,72.3 \%)$ than in trauma patients $(n=225,27.7 \%)$. In comparison, HIVnegative patients reported fewer medical complaints $(n=1$ 137, 54.4\%) and more trauma $(n=953,45.6 \%)(p<0.001)$. HIV-positive patients were more likely to have a life-threatening emergency $(n=192,23.7 \%)(p=0.004)$, to be critically ill by triage score $(p<0.001)$ and to be admitted to the hospital $(p<0.001)$ than those who were HIV-negative. Despite high acuity overall, people living with HIV/AIDS were significantly less likely to be deemed critically ill according to vital signs (adjusted PR $0.94 ; p=0.046$ ).

Conclusions. While EDs in SA provide care to high volumes of patients with trauma-related injuries, in areas where HIV prevalence is highest, patients are more likely to present with acute medical emergencies. Providers of emergency care in SA need to be well versed in the management of HIV and associated complications.
\end{abstract}

S Afr Med J 2020;110(3):217-222. https://doi.org/10.7196/SAMJ.2020.v110i3.14174

South Africa (SA) continues to endure a triple burden of severe disease characterised by HIV/AIDS and other communicable diseases, injuries, and an increasing prevalence of chronic non-communicable diseases (NCDs). ${ }^{[1]}$ In 2016, the prevalence of HIV in SA was estimated to be $12.8 \%$, rising to as high as $19.1 \%$ in individuals aged 15 - 49 years. ${ }^{[2]}$ The leading cause of death was reported as accidental injuries, accounting for $7.5 \%$ of all deaths. ${ }^{[3]}$ Heart disease (10.2\%), tuberculosis (TB) (6.5\%), diabetes mellitus (5.5\%) and HIV (4.8\%) were among the 10 leading causes of natural death. ${ }^{[3]}$ The number of people living with HIV (PLWH) and diagnosed with one or more NCDs is rising as a result of both the increased risk of developing NCDs in HIV-positive individuals and the evolution of HIV into a treatable chronic condition due to effective antiretroviral therapy. ${ }^{[4]}$ HIV-positive individuals are predicted to have a $26 \%$ increased likelihood of being diagnosed with at least one NCD over time (33\% in $2015,59 \%$ in 2035), compared with a $6 \%$ increase in likelihood for HIV-negative individuals ( $14 \%$ in $2015,20 \%$ in 2035). ${ }^{[5]}$ In addition, antiretroviral (ARV) medications are known to have a number of complications that predispose PLWH to developing cardiovascular, neurological, muscular, liver, bone and/or immune system disorders as a result of accumulated drug toxicity. ${ }^{[4,6]}$ Current research on HIV infection and associated comorbidities also points towards an increasingly high baseline prevalence of NCDs and other comorbidities in specific populations of interest. ${ }^{[7-1]}$

In countries like SA, emergency departments (EDs) are safety nets within a public healthcare system, providing care to patients who are unable to access or seek primary care services; in this context, EDs are known to manage a significant proportion of the acute health burden in SA, much of which is related to trauma and HIV, and are statutorily required by the Constitution of SA to provide emergency care to everyone. ${ }^{[12,13]}$ Global burden of disease data suggest that over half of the reported mortality and $35 \%$ of disability in low- and middle-income countries (LMICs) may be attributable to the lack of quality emergency care services. ${ }^{[14]}$ EDs in SA are typically staffed by junior doctors and/or medical officers with little if any training in emergency medicine, and while emergency care has received more attention in SA than in many LMICs, EDs still suffer from a lack of resources, staff and equipment. ${ }^{[15,16]}$

Given SA's endemic burden of HIV infection overall, and recent data suggesting a high burden of PLWH presenting to EDs, EDs have 
a critical role in providing health services to PLWH. ${ }^{[13]}$ A holistic approach to the care of PWLH requires determining the type of care and services HIV-positive individuals require. Beyond the use of EDs to identify HIV-positive individuals, ${ }^{[17]}$ there is a need to meet the changing needs of patients with both NCDs and HIV through understanding the impact of NCDs on morbidity and mortality in this population.

\section{Objectives}

To define the burden of comorbidities in HIV-positive ED patients and describe their demographic profiles and severity of illness compared with the general ED population, in order to make recommendations for resource allocation and training in EDs in SA.

\section{Methods}

This cross-sectional observational study was conducted between June 2017 and July 2018 . During the study period we implemented point-of-care (POC) HIV testing in accordance with national testing guidelines, and collected data on patient demographics, chief complaint, severity of illness, medical history and course of care throughout the ED. A detailed description of the Walter Sisulu Infection Screening in the Emergency Department (WISE) study methodology is provided elsewhere. ${ }^{[18]}$ An overview of the study procedures is provided in Fig. 1.

The study was conducted in the EDs of three hospitals in Mthatha and Port Elizabeth in Eastern Cape Province. Both Nelson Mandela Academic Hospital (NMAH) and Mthatha Regional Hospital $(\mathrm{MRH})$ are located in Mthatha, and Livingstone Hospital (LH) is located in Port Elizabeth. All three hospitals provide 24-hour services and receive patients from up to $200 \mathrm{~km}$ away. NMAH and $\mathrm{LH}$ are tertiary-care centres, while MRH is a district-level hospital that refers trauma patients to NMAH. The EDs receive 100 150 patients per day, have $<50$ beds, and are staffed by medical officers and nurses with limited formal emergency medicine training. Patient medical records are kept in paper files, and handwritten logbooks are used as patient tracking systems in the EDs of all three hospitals.

All patients who presented for care to the EDs during the study period, who were aged $\geq 18$ years and were fully conscious and clinically stable, were eligible for enrolment. Patients were approached after being triaged in the ED.

The primary outcome measure was the prevalence of comorbidities and co-infection among PLWH in the ED. Secondary outcome measures included patient characteristics such as severity of illness, presenting complaint, and the course of care in the ED. Medical history was obtained via patient selfreport. HIV counselling and testing (HCT) staff used a standardised case report form (CRF) to collect data. Presenting complaints were recorded as free text and coded using Medical Dictionary for Regulatory Activities (MedDRA; MedDRA MSSO, USA). Data were collected prospectively on CRFs by HCT staff, who also noted whether or not subjects consented to a rapid POC HIV test, and their POC HIV results. Data forms were scanned and entered using intelligent character recognition DataFax software (Clinical DataFax Systems Inc., Canada) and centrally double-verified by independent data technicians.

Data were analysed using a descriptive statistical approach using Stata version 15 (StataCorp, USA). The overall prevalence of comorbidities and co-infections in HIV-positive patients was calculated by including patients with a known history of HIV infection and newly identified HIV-positive patients via HCT in the ED. The prevalence of HIV with regard to demographic characteristics and the clinical outcomes of interest was examined using descriptive analysis. Log-binomial and modified Poisson models were used to examine the association between HIV status and clinical outcomes using crude (unadjusted) and adjusted prevalence ratios (PRs).

The Johns Hopkins University School of Medicine Institutional Review Board (ref. no. IRB00105801), the Walter Sisulu University Human Research Ethics Committee (ref. no. 002/2016) and the University of Cape Town Human Research Ethics Committee (ref. no. 401/2013) approved the study. All participants enrolled provided written consent to receive a POC HIV test and have detailed demographic data collected both on their reason for presentation and their ED course.

\section{Results}

A total of 8000 patients presented to the EDs during the study period, of whom 3537 (44.2\%) were enrolled in the WISE study; $636(18.0 \%)$ refused an HIV test, and their HIV status remains unknown. The overall HIV prevalence in those with an HIV test result or a history of HIV ( $n=2901$ ) was $28.0 \%$ (811/2 901). Of these individuals, 577 (71.1\%) reported a known diagnosis of HIV and 234 (28.9\%) were

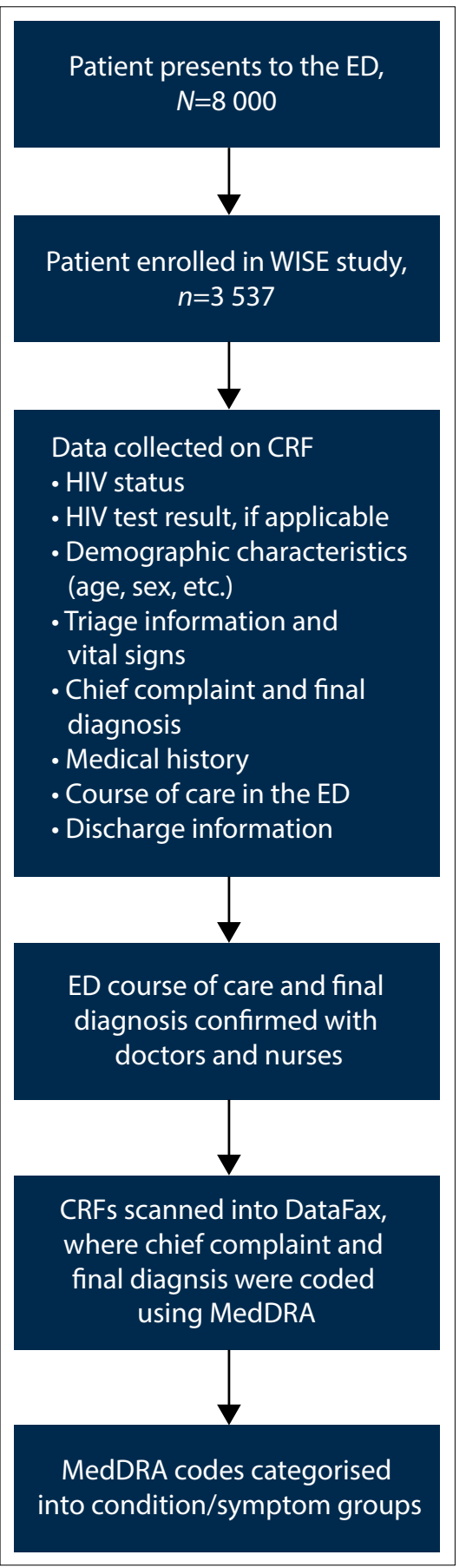

Fig. 1. Comorbidity and co-infection study procedure overview. ( $E D=$ emergency department ; WISE $=$ Walter Sisulu Infection Screening in the Emergency Department; $C R F=$ case report form; MedDRA = Medical Dictionary for Regulatory Activities.)

diagnosed through POC testing in the ED and had previously been unaware of their status.

The majority of individuals with a new HIV-positive diagnosis were aged $\leq 35$ years (64.5\%). More women (69.1\%) than men reported a known diagnosis of HIV at the 
time of enrolment. Medical complaints were more frequent $(72.3 \%)$ in the HIV-positive group (including known and newly positive patients), whereas the proportions of medical and trauma complaints were similar in HIV-negative patients (54.5\% and $45.6 \%$, respectively). Almost $25 \%$ of $\mathrm{HIV}$-positive individuals were considered to have a lifethreatening emergency, defined as a triage level of emergency or very urgent according to the South African Triage Scale (SATS), ${ }^{[19]}$ compared with $\sim 20 \%$ of HIV-negative individuals. As suggested by the degree of acuity of presentation, a substantially larger proportion of HIV-positive than HIV-negative individuals required hospital admission (27.1\% v. $20 \%$; $p<0.001)$.

HIV-positive patients were likely to be young and female (Table 1). When chief complaints were categorised to provide a more in-depth overview of complaints most frequently seen in the $\mathrm{ED}$, the top five presenting medical and trauma complaints were similar for both groups, although these complaints occurred at different frequencies.

Within the top five complaints, injuries from interpersonal violence accounted for a substantially higher proportion in the HIV-negative population than in the positive population (Fig. 2). For medical presentations, abdominal pain $(16.5 \%$ v. $17.3 \%)$, chest pain $(4.3 \%$ v. $9.3 \%)$ and shortness of breath ( $16.7 \%$ v. $14.2 \%)$ accounted for $\sim 40 \%$ of all medical complaints across both the HIV-positive and HIV-negative groups. (37.5\% v. $40.8 \%$; $p<0.001)$. Differences between HIV-positive and negative patients were noted to include generalised weakness and headache as a more common complaint in PLWH.

The prevalences of NCDs, infections, and social determinants of health (suicidal ideation/depression, excessive alcohol consumption and regular tobacco use) were calculated for HIV-positive, HIV-negative and all patients (Table 2). Case definitions were used to estimate the number of individuals with septicaemia, pneumonia, weight loss and TB symptoms. Table 2 provides a $\chi^{2}$ analysis of each illness, demonstrating significant differences when stratifying by HIV status for coexisting diabetes $(p<0.001)$, cardiovascular disease (CVD) $(p=0.003)$, hypertension $(p<0.001)$, diagnosed TB $(p<0.001)$, excessive alcohol consumption $(p<0.001)$, sepsis $(p=0.006)$, pneumonia $(p<0.001)$ and symptoms indicating TB infection $(p<0.001)$. Unsurprisingly, diagnosed TB (16.1\%) and symptoms indicating TB infection (19.2\%) were significantly more prevalent in the HIV-positive population $(4.1 \%)$ than in the HIV-negative population $(4.8 \%)$. Pneumonia was also significantly more prevalent in the HIVpositive population (12.9\%). In contrast, and while limited owing to low numbers, it is notable that overall frequency of liver disease (4/2 901, 0.1\%) and coinfection with hepatitis $\mathrm{B}$ and hepatitis $\mathrm{C}$ were quite low, with only $1(0.03 \%)$ HIV-positive individual reporting a history of hepatitis $\mathrm{B}$ and no case of hepatitis C. One limitation of the data is that it is not clear whether the low frequency of liver disease, hepatitis B and hepatitis C represents lack of diagnosis or true absence of disease. Significantly higher frequencies of diabetes $(7.8 \%$ v. $2.8 \% ; p<0.001)$ and hypertension $(20.1 \%$ v. $9.6 \%, p<0.001)$ in the HIV-negative group may also relate to issues of diagnosis and age, in view of the substantially higher proportion of the HIVnegative group aged $>55$ years. As seen in Table 2, similar rates of social determinants of health were seen in terms of mental health and tobacco use, but excessive alcohol use was more frequent in the HIV-negative group (36.3\% v. $24.4 \%$; $p<0.001)$.

Table 3 presents the unadjusted PR and the PR adjusted for age and sex for HIVpositive individuals across various clinical outcomes. Compared with HIV-negative individuals, PLWH were twice as likely to have pneumonia $(p<0.001)$, four times as likely to have symptoms indicating $\mathrm{TB}$ $(p<0.001)$, and three times as likely to have sepsis $(p<0.001)$. Excessive alcohol consumption was the only significant social determinant (adjusted PR 0.72; $p<0.001$ ). PLWH were 1.36 times more likely to be critically ill by triage score $(p<0.001)$ and 1.32 times more likely to be admitted to the hospital $(p<0.001)$ than HIV-negative individuals. Despite high acuity overall, PLWH were found to be significantly less likely to be deemed critically ill by vital signs (adjusted PR 0.94; $p=0.046$ ). There was no significant difference between HIV status groups for emergency surgery.

\section{Discussion}

A high proportion of ED patients in the Eastern Cape were HIV-positive (28.0\%), and there was a high prevalence of undiagnosed HIV in the ED (6.6\%). While the overall presenting complaints among HIV-positive and HIV-negative individuals were similar, PLWH were significantly more likely to present with weakness and breathlessness and to meet case definitions for sepsis, respiratory illness or TB-associated complaints. Furthermore, PLWH were sicker and more likely to be admitted.

Interestingly, while PLWH presenting to the ED were likely to be sicker than HIV-negative patients and were more likely to have an urgent $(63.9 \%)$ or very urgent $(22.9 \%)$ triage designation, a triage strategy based on vital signs only would have failed to recognise this degree of acuity. The accuracy of the SATS in triaging these patients as likely to need significant emergency resources despite relatively normal vital signs is also reflected in the fact that a significantly higher proportion of $\mathrm{PLWH}$ (27.1\%) than HIV-negative patients $(20.0 \%)$ were admitted.

Considering all patients, non-accidental stab wounds/cuts (12.6\%), abdominal pain $(10.1 \%)$ and shortness of breath $(8.3 \%)$ were the most frequently reported chief complaints in the present study. These are similar to those reported in other studies examining chief complaints in Africa. ${ }^{[20,21]}$ In the present study, assault-related chief complaints (stab wounds/cuts and bluntforce injuries) appeared twice in the top five overall complaints for HIV-negative patients,

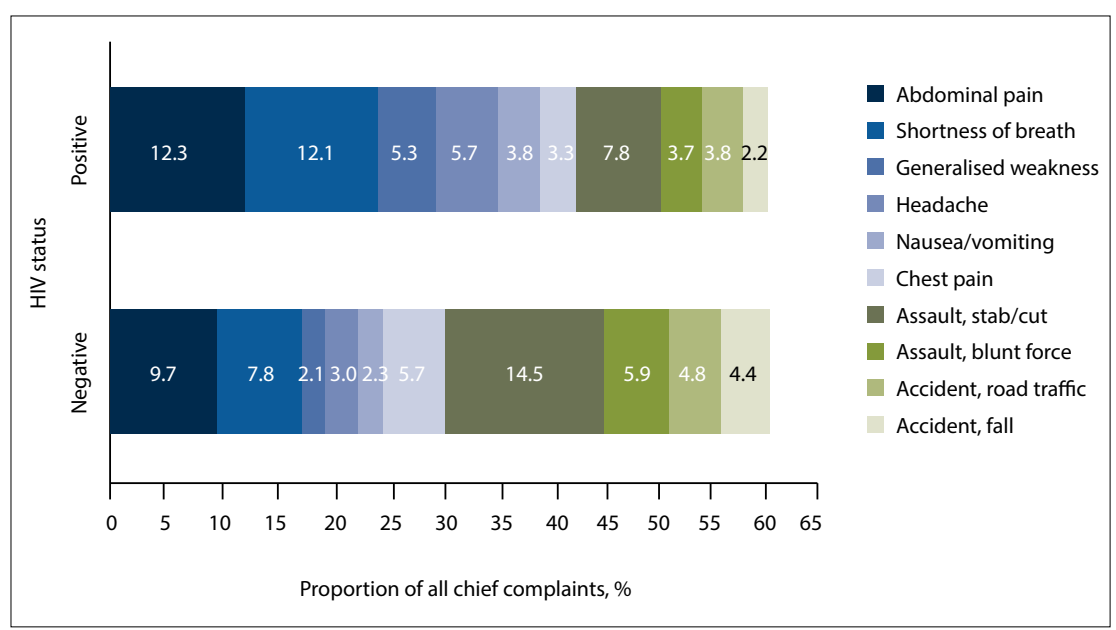

Fig. 2. Proportion of complaints represented by the top 10 chief complaints, according to HIV status. 


\begin{tabular}{|c|c|c|c|c|}
\hline & $\begin{array}{l}\text { HIV-positive } \\
(N=811), n(\%)\end{array}$ & $\begin{array}{l}\text { HIV-negative } \\
(N=2 \text { 090), } n(\%)\end{array}$ & $\begin{array}{l}\text { Total }(N=2901) \text {, } \\
n(\%)\end{array}$ & $\chi^{2}(p$-value $)$ \\
\hline Age (years) & & & & $198.6019(<0.001)^{*}$ \\
\hline$<20$ & $11(1.4)$ & $121(5.8)$ & $132(4.5)$ & \\
\hline $20-25$ & $111(13.7)$ & $431(20.6)$ & $542(18.7)$ & \\
\hline $26-35$ & $290(35.8)$ & $526(25.2)$ & $816(28.1)$ & \\
\hline $36-45$ & $224(27.6)$ & $276(13.2)$ & $500(17.2)$ & \\
\hline $46-55$ & $105(12.9)$ & $253(12.1)$ & $358(12.3)$ & \\
\hline$>55$ & $70(8.6)$ & $483(23.1)$ & $553(19.1)$ & \\
\hline Sex & & & & $76.3401(<0.001)^{*}$ \\
\hline Male & $302(37.2)$ & $1156(55.3)$ & $1458(50.3)$ & \\
\hline Female & $509(62.8)$ & $934(44.7)$ & $1443(49.7)$ & \\
\hline \multicolumn{5}{|l|}{ Presenting complaint } \\
\hline Medical & $586(72.3)$ & $1137(54.4)$ & $1723(59.4)$ & $32.2142(<0.001)^{*}$ \\
\hline Abdominal pain & $97(16.5)$ & $197(17.3)$ & $294(17.1)$ & \\
\hline Chest pain & $25(4.3)$ & $106(9.3)$ & $131(7.6)$ & \\
\hline Generalised weakness & $43(7.3)$ & $45(4.0)$ & $88(5.1)$ & \\
\hline Headache & $43(7.3)$ & $52(4.6)$ & $95(5.1)$ & \\
\hline Nausea/vomiting & $31(5.3)$ & $48(4.2)$ & $79(4.6)$ & \\
\hline Pain & $24(4.1)$ & $50(4.4)$ & $74(4.3)$ & \\
\hline Seizure/convulsion & $19(3.2)$ & $55(4.8)$ & $74(4.3)$ & \\
\hline Shortness of breath & $98(16.7)$ & $161(14.2)$ & $259(15.0)$ & \\
\hline Swelling & $21(3.6)$ & $45(4.0)$ & $66(3.8)$ & \\
\hline Vaginal bleeding & $22(3.7)$ & $35(3.1)$ & $57(3.3)$ & \\
\hline Trauma & $225(27.7)$ & $953(45.6)$ & $1178(40.6)$ & $8.3754(0.497)$ \\
\hline Accident, fall & $18(8.0)$ & $93(9.8)$ & $111(9.4)$ & \\
\hline Accident, road traffic & $31(13.8)$ & $101(10.6)$ & $132(11.2)$ & \\
\hline Accident, stab/cut & $9(4.0)$ & $17(1.8)$ & $26(2.2)$ & \\
\hline Assault, animal/human bite & $6(2.7)$ & $34(3.6)$ & $40(3.4)$ & \\
\hline Assault, blunt force & $30(13.3)$ & $123(12.9)$ & $153(13.0)$ & \\
\hline Assault, gunshot wound & $24(2.5)$ & $24(2.5)$ & $28(2.4)$ & \\
\hline Assault, stab/cut & $63(28.0)$ & $303(31.8)$ & $366(31.1)$ & \\
\hline Burn & $5(2.2)$ & $21(2.2)$ & $26(2.2)$ & \\
\hline Joint pain & $5(2.2)$ & $26(2.7)$ & $31(2.6)$ & \\
\hline Pain & $18(8.0)$ & $69(7.2)$ & $87(7.4)$ & \\
\hline SATS & & & & $30.3785(<0.001)^{\star}$ \\
\hline Emergency & $6(0.7)$ & $17(0.8)$ & $23(0.8)$ & \\
\hline Very urgent & $186(22.9)$ & $378(18.1)$ & $564(19.4)$ & \\
\hline Urgent & $510(62.9)$ & $1235(59.1)$ & $1745(60.1)$ & \\
\hline Routine & $109(13.4)$ & $460(22.0)$ & $569(19.6)$ & \\
\hline Disposition & & & & $57.4243(<0.001)^{*}$ \\
\hline Death & $3(0.4)$ & $4(0.2)$ & $7(0.2)$ & \\
\hline Admission & $220(27.1)$ & $419(20.0)$ & $639(22.0)$ & \\
\hline ICU admission & $1(0.1)$ & $2(0.1)$ & $3(0.1)$ & \\
\hline Emergency surgery & $22(2.7)$ & $65(3.1)$ & $87(3.0)$ & \\
\hline Transfer & $89(11.0)$ & $208(9.9)$ & $297(10.2)$ & \\
\hline Discharge & $400(49.3)$ & $1259(60.2)$ & $1659(57.2)$ & \\
\hline Absconded & $14(1.7)$ & $66(3.2)$ & $80(2.8)$ & \\
\hline Unknown & $62(7.6)$ & $67(3.2)$ & $129(4.4)$ & \\
\hline
\end{tabular}

whereas only assault-related stab wounds/cuts appeared in the top five overall complaints for those who were HIV-positive. Considering that $\sim 30 \%$ of all trauma complaints occurred in HIV-positive patients, these patients represent a potential missed population for HIV testing and diagnosis, and it is important that patients presenting with trauma complaints are tested for HIV.
Overall, PLWH were more likely to present with medical than traumatic complaints. Abdominal pain and shortness of breath were the top two medical complaints for both HIV-positive (16.5\% and $16.7 \%$, respectively) and HIV-negative $(17.3 \%$ and $14.2 \%$, respectively) patients. Generalised weakness (7.3\%) and nausea/ vomiting $(5.3 \%)$ were in the top five chief medical complaints for 
Table 2. Prevalence of comorbidities and co-infections according to HIV status

\begin{tabular}{|c|c|c|c|c|}
\hline & $\begin{array}{l}\text { HIV-positive } \\
(N=811), n(\%)\end{array}$ & $\begin{array}{l}\text { HIV-negative } \\
(N=2 \text { 090), } n \text { (\%) }\end{array}$ & $\begin{array}{l}\text { Total }(N=2901) \text {, } \\
n(\%)\end{array}$ & $\chi^{2}(p$-value $)$ \\
\hline \multicolumn{5}{|l|}{ Presenting complaints } \\
\hline Sepsis & $20(2.5)$ & $23(1.1)$ & $43(1.5)$ & $7.4617(0.006)^{*}$ \\
\hline Pneumonia & $105(12.9)$ & $169(8.1)$ & $274(9.4)$ & $16.1410(<0.001)^{\star \star}$ \\
\hline Weight loss & $2(0.2)$ & $4(0.2)$ & $6(0.2)$ & $0.0863(0.769)$ \\
\hline TB symptoms & $156(19.2)$ & $101(4.8)$ & $257(8.9)$ & $150.1152(<0.001)^{* *}$ \\
\hline \multicolumn{5}{|l|}{ Medical history } \\
\hline Asthma/COPD & $35(4.3)$ & $143(6.8)$ & $178(6.1)$ & $6.4754(0.011)^{*}$ \\
\hline Cancer & $3(0.4)$ & $11(0.5)$ & $14(0.5)$ & $0.2976(0.585)$ \\
\hline Diabetes & $23(2.8)$ & $163(7.8)$ & $186(6.4)$ & $23.9843(<0.001)^{\star *}$ \\
\hline Epilepsy & $16(2.0)$ & $45(2.1)$ & $61(2.1)$ & $0.0922(0.761)$ \\
\hline CVD & $3(0.4)$ & $38(1.8)$ & $41(1.4)$ & $8.7955(0.003)^{\star}$ \\
\hline Hypertension & $78(9.6)$ & $420(20.1)$ & $498(17.2)$ & $45.1111(<0.001)^{* *}$ \\
\hline Hepatitis B & $1(0.1)$ & 0 & $1(0.03)$ & $2.5780(0.108)$ \\
\hline Kidney disease & $1(0.1)$ & $13(0.6)$ & $14(0.5)$ & $3.0257(0.082)$ \\
\hline Liver disease & $3(0.4)$ & $1(0.05)$ & $4(0.1)$ & $4.4015(0.036)^{\star}$ \\
\hline History of TB & $131(16.1)$ & $86(4.1)$ & $217(7.5)$ & $122.3449(<0.001)^{* *}$ \\
\hline Mental illness & $30(3.7)$ & $88(4.2)$ & $118(4.1)$ & $0.3916(0.531)$ \\
\hline \multicolumn{5}{|l|}{ Social history } \\
\hline Suicidal ideation/ depression & $28 / 806(3.5)$ & $80 / 2077(3.8)$ & $108 / 2883(3.7)$ & $0.2298(0.632)$ \\
\hline Excessive alcohol consumption & $197 / 806(24.4)$ & $756 / 2080(36.3)$ & $953 / 2886(33.0)$ & $37.2212(<0.001)^{* *}$ \\
\hline Regular tobacco use & $177 / 807(21.9)$ & $509 / 2078(24.5)$ & $686 / 2885(23.8)$ & $2.1045(0.147)$ \\
\hline
\end{tabular}

Table 3. Prevalence of clinical outcome if HIV-positive

\begin{tabular}{|c|c|c|c|c|c|c|}
\hline & \multicolumn{3}{|c|}{ Unadjusted } & \multicolumn{3}{|c|}{ Adjusted $^{\dagger}$} \\
\hline & PR & $95 \% \mathrm{CI}$ & $p$-value & PR & $95 \% \mathrm{CI}$ & $p$-value \\
\hline \multicolumn{7}{|l|}{ Co-illness } \\
\hline Pneumonia & 1.60 & $1.27-2.01$ & $<0.001^{* *}$ & 2.08 & $1.65-2.62$ & $<0.001^{*}$ \\
\hline $\mathrm{TB}$ & 3.98 & $3.14-5.04$ & $<0.001^{\star *}$ & 4.30 & $3.40-5.43$ & $<0.001^{\star}$ \\
\hline Sepsis & 2.61 & $1.18-5.79$ & $0.018^{* *}$ & 3.18 & $1.34-7.57$ & $0.009^{*}$ \\
\hline \multicolumn{7}{|l|}{ Social determinants } \\
\hline Excessive alcohol consumption & 0.67 & $0.59-0.77$ & $<0.001^{* *}$ & 0.72 & $0.63-0.83$ & $<0.001^{*}$ \\
\hline Regular tobacco use & 0.89 & $0.77-1.04$ & 0.150 & 1.05 & $0.90-1.22$ & 0.516 \\
\hline Mental illness & 0.88 & $0.58-1.32$ & 0.532 & 0.75 & $0.49-1.17$ & 0.206 \\
\hline Victim of violence & 0.96 & $0.82-1.11$ & 0.554 & 1.05 & $0.90-1.22$ & 0.528 \\
\hline \multicolumn{7}{|l|}{ ED outcomes } \\
\hline Critically ill by triage & 1.25 & $1.07-1.46$ & $0.004^{* \star}$ & 1.36 & $1.16-1.60$ & $<0.001^{\star}$ \\
\hline Critically ill by vitals only & 0.96 & $0.90-1.02$ & 0.184 & 0.94 & $0.88-1.00$ & $0.046^{*}$ \\
\hline Admission & 1.23 & $1.11-1.37$ & $<0.001^{\star *}$ & 1.32 & $1.18-1.47$ & $<0.001^{\star}$ \\
\hline Emergency surgery & 0.91 & $0.57-1.47$ & 0.712 & 0.98 & $0.60-1.60$ & 0.947 \\
\hline
\end{tabular}

HIV-positive patients, but not for HIV-negative patients. These complaints are potentially linked to symptoms associated with HIV infection or side-effects of ARV medications and have implications for emergency care provider training. ${ }^{[22]}$

The common co-infections in PLWH in the present study reflect the conditions likely to result in hospital admission rather than the comorbid conditions associated with chronic ambulatory HIV care such as hepatitis B and C, malaria, sexually transmitted infections and cervical cancer, as outlined in the World Health Organization Consolidated Guidelines on the Use of Antiretroviral Drugs for Treating and Preventing HIV Infection. ${ }^{[4]}$ Few HIV-positive patients in our study reported these diseases in their medical history. Only one case of hepatitis B ( $0.1 \%$ prevalence) was reported in the HIV-positive population. The chronic hepatitis B infection prevalence for HIVpositive individuals worldwide is estimated as $5-20 \%$, much higher than what we report in the present study. ${ }^{[4]}$ Additionally, various studies in SA have found a relatively low prevalence of hepatitis B and hepatitis $\mathrm{C}$, even in PLWH. ${ }^{[23,24]}$ These findings may indicate true low rates, influenced by the fact that HIV transmission in the Eastern Cape is more closely linked with sexual transmission than transmission via injection drug use. ${ }^{[25]}$ With the Eastern Cape having high rates of $\mathrm{TB},{ }^{[26]}$ it is not surprising that a high proportion of 
HIV-positive individuals screened positive for TB (19.2\%) or were diagnosed with TB (16.1\%). The nonspecific nature of presenting complaints may also underestimate the burden of $\mathrm{TB}$ in the population of PLWH presenting to the $\mathrm{ED}$, as demonstrated in lipoarabinomannan screening studies, ${ }^{[27-29]}$ and presents an opportunity for improved TB screening in this subgroup. The other acute presentations are likely to represent the increased incidence of bacterial infection, pneumocystis pneumonia and cryptococcal disease associated with HIV infection. ${ }^{[30]}$

As the life expectancy of HIV-positive individuals continues to increase, it is important to monitor non-communicable comorbidities such as CVD, hypertension, diabetes, chronic obstructive pulmonary disease, kidney disease and cancer, owing to the increased risk of development at younger ages than is typical in HIV-negative patients. ${ }^{[31-36]}$ While these differences were not found in our study population, we suspect that this is because the ED patients in this study may have represented a younger HIV-positive cohort.

\section{Study limitations}

This study was limited by the collection of comorbidity and co-infection data secondary to the HIV data that were the focus of the WISE study. A study focused on the collection of HIV comorbidity and co-infection data and clinical outcomes would have implemented a different recruitment and enrolment process. However, the collection of comorbidity and co-infection information through the WISE study allowed for prospective collection of data, enabling the data to be more accurate than with retrospective chart review in the same setting.

\section{Conclusions}

While EDs in SA provide care to high volumes of patients with trauma-related injuries, in areas where the prevalence of HIV is highest, HIV-positive patients are still more likely than those who are HIV-negative to present with acute medical emergencies rather than trauma. The service delivery implications of the present study include recognition that compared with HIV-negative patients, HIV-positive patients are often sicker and have more comorbidities (although not necessarily with traditional NCDs), and frequently require admission, triage and ED resources. Training must focus on early identification and treatment of HIV-associated complications in the ED.

\section{Declaration. None.}

Acknowledgements. The authors acknowledge the staff in the accident and emergency departments at LH, NMAH and MRH for making this study possible, and the study co-ordinators and HIV counsellors for their hard work throughout the study.

Author contributions. EAH and BH conceptualised the study and supervised implementation. GM provided support in completing the statistical analysis. JB and RM provided in-country support of the study team. EAH and BH drafted the manuscript, and all other authors contributed meaningfully. All authors approved the final version of the manuscript.

Funding. This study was funded by the National Institute on Drug Abuse and the Division of Intramural Research, National Institute of Allergy and Infectious Diseases, National Institutes of Health, USA, and the South African Medical Research Council.

\section{Conflicts of interest. None.}

1. Bradshaw D, Groenewald P, Laubscher R, et al. Initial burden of disease estimates for South Africa, 2000. S Afr Med J 2003;93(9):682-688

2. South African National AIDS Council. South Africa’s National Strategic Plan for HIV, TB and STIs 2017 - 2022. 2017. https://sanac.org.za//wp-content/uploads/2017/06/NSP_FullDocument_FINAL.pdf (accessed 18 July 2018).
3. Statistics South Africa. Mortality and causes of death in South Africa, 2016: Findings from death notification. Statistical release P0309.3. Pretoria: Stats SA, 2017. http://www.statssa.gov.za/publications/ P03093/P030932016.pdf (accessed 10 August 2018).

4. World Health Organization. Consolidated Guidelines on the use of Antiretroviral Drugs for Treating and 4. World Health Organization. Consolidated Guidelines on the use of Antiretroviral Drugs for Treating and
Preventing HIV Infection: Recommendations for a Public Health Approach. 2013. https://apps.who.int/ Preventing HIV Infection: Recommendations for a Public Health Approach. 2013. https://apps.who.int/
iris/bitstream/handle/10665/208825/9789241549684_eng.pdf;jsessionid=8C6FB744568B3F67B219B48 iris/bitstream/handle/10665/208825/9789241549

5. Smit M, Olney J, Ford N, et al. The growing burden of noncommunicable disease among persons living 5. Smit M, Olney J, Ford N, et al. The growing burden of noncommunicable disease among persons living
with HIV in Zimbabwe. AIDS 2018;32(6):773-782. https://doi.org/10.1097/qad.0000000000001754 with HIV in Zimbabwe. AIDS 2018;32(6):773-782. https://doi.org/10.1097/qad.0000000000001754 J Antivir Antiretrovir 2011;3(4):060-064. https://doi.org/10.4172/jaa.1000037

7. Nlooto M. Comorbidities of HIV infection and health care seeking behavior among HIV infected Nlooto M. Comorbidities of HIV infection and health care seeking behavior among HIV infected
patients attending public sector healthcare facilities in KwaZulu-Natal: A cross sectional study. PLoS One patients attending public sector healthcare facilities in KwaZulu-Natal: A cross sectional study. PLoS One 2017;12(2):1-15. https://doi.org/10.1371/journal.pone.017098

8. Magafu M, Moji K, Igumbor E, et al. Non-communicable diseases in antiretroviral therapy recipients in Kagera Tanzania: A cross-sectional study. Pan Afr Med J 2013;16(84):1-8. https://doi.org/10.11604/ pamj.2013.16.84.2831

9. Semeere A, Sempa J, Lwanga I, Parkes-Ratanshi R, Kambugu A. Hypertension and associated risk factors in individuals infected with HIV on antiretroviral therapy at an urban HIV clinic in Uganda. Lancet Glob Health 2014;2(1):S23. https://doi.org/10.1016/S2214-109X(15)70045-8

10. Kavishe B, Biraro S, Baisley K, et al. High prevalence of hypertension and of risk factors for noncommunicable diseases (NCDs): A population based cross-sectional survey of NCDs and HIV infection in northwestern Tanzania and southern Uganda. BMC Med 2015;13(126):1-21. https://doi.org/10.1186/ s12916-015-0357-9

11. Levitt N, Bradshaw D, Dave J, Bradshaw D. Chronic noncommunicable diseases and HIV-AIDS on a collision course: Relevance for health care delivery, particularly in low-resource settings - insights from South Africa. Am J Clin Nutr 2011;94(6):1690S-1696S. https://doi.org/10.3945/ajcn.111.019075

12. Gottschalk S, Wood D, DeVries S, Wallis L, Bruijns S. The Cape Triage Score: A new triage system South Africa. Proposal from the Cape Triage Group. Emerg Med J 2006;23(2):149-153. https://doi.org/10.1136/ emj.2005.028332

13. South African Government. The Constitution of the Republic of South Africa, 1996. https://www.gov.za/ sites/default/files/images/a108-96.pdf (accessed 30 August 2018).

14. Thind A, Hsia R, Mabweijano J, Hicks E, Zakariah A, Mock C. Prehospital and emergency care. In: Debas H, Donkor P, Gawande A, Jamison D, Kruk M, Mock C, eds. Disease Control Priorities. 3rd ed. Washington, DC: World Bank, 2015:245

15. Wallis L, Garach S, Kropman A. State of emergency medicine in South Africa. Int J Emerg Med 2008;1(2):69-71. https://doi.org/10.1007/s12245-008-0033-3

16. Holliman C, Mulligan T, Suter R, et al. The efficacy and value of emergency medicine: A supportive literature review. Int J Emerg Med 2011;4:44. https://doi.org/10.1186/1865-1380-4-44

17. Hardcastle T, Hansoti B. HIV, trauma and the emergency departments: The CDC opt-out approach should be adopted in South Africa. S Afr J Bioethics Law 2016;9(2):57-60. https://doi.org/10.7196/ SAJBL.2016.v9i2.486

18. Hansoti B, Stead D, Parrish A, et al. HIV testing in a South African emergency department: A missed opportunity. PLoS One 2018;13(3):e0193858-e0193872. https://doi.org/10.1371/journal.pone.0193858 9. Western Cape Government. The South African Triage Scale (SATS): Training Manual 2012. https:// emssa.org.za/wp-content/uploads/2011/04/SATS-Manual-A5-LR-spreads.pdf (accessed 1 August 2018).

20. Oteng R, Whiteside L, Rominski S, et al. Individual and medical characteristics of adults presenting to an urban emergency department in Ghana. Ghana Med J 2015;49(3):136-141. https://doi.org/10.4314/ gmj.v49i3.2

21. Myers J, Hunold K, Ekernas K, et al. Patient characteristics of the Accident and Emergency Department of Kenyatta National Hospital, Nairobi, Kenya: A cross-sectional, prospective analysis. BMJ Open of Kenyatta National Hospital, Nairobi, Kenya: A cross-sectional, prospective
2017;7(10):e014974-e014983. https://doi.org/10.1136/bmjopen-2016-014974

22. US Department of Health and Human Services. HIV medicines and side effects. 2019. https://aidsinfonih. gov/understanding-hiv-aids/fact-sheets/22/63/hiv-medicines-and-side-effects (accessed 15 May 2019).

23. Bristol-Myers Squibb Foundation. Viral hepatitis C initiative for key populations in South Africa. 2019. http://www.nicd.ac.za/wp-content/uploads/2019/03/Results_SA_Viral_Hepatitis_Study_2018.pdf (accessed 3 May 2019).

4. Boyles T, Cohen K. The pre Med 2011:101(7):470-471

25. Firnhaber $C$. Beyneke $A$, Schulze $D$, et al. The prevalence of hepatitis $B$ co-infection in a South African urban government HIV clinic. S Afr Med J 2008;98(7):541-544.

26. Massyn N, Peer N, English R, Padarath A, Barron P, Day C, eds. District Health Barometer 2015/16. Durban: Health Systems Trust, 2016. https://www.hst.org.za/publications/District\%20Health\%20 Barometers/District\%20Health\%20Barometer\%202015_16.pdf (accessed 10 August 2018).

27. Peter J, Zijenah L, Chanda D, et al. Effect on mortality of point-of-care, urine-based lipoarabinomannan testing to guide tuberculosis treatment initiation in HIV-positive inpatients: A pragmatic, parallel-group, multicountry, open-label, randomised controlled trial. Lancet 2016;387(10024):1187-1197. https://doi. $\mathrm{org} / 10.1016 / \mathrm{s} 0140-6736(15) 01092-2$

28. Gupta-Wright A, Corbett E, van Oosterhout J, et al. Rapid urine-based screening for tuberculosis in HIV-positive patients admitted to hospital in Africa (STAMP): A pragmatic, multicentre, parallel-group, double-blind, randomised controlled trial. Lancet 2018;392(10144):292-301. https://doi.org/10.1016/ 30140-6736(18)31267-4

29. Lawn S, Kerkhoff A, Burton R, et al. Diagnostic accuracy, incremental yield and prognostic value of Determine TB-LAM for routine diagnostic testing for tuberculosis in HIV-infected patients requiring acute hospital admission in South Africa: A prospective cohort. BMC Med 2017;15(1):67-83. https://doi. org/10.1186/s12916-017-0822-8

30. World Health Organization. Guidelines for Managing Advanced HIV Disease and Rapid Initiation of Antiretroviral Therapy. 2017. https://apps.who.int/iris/bitstream/handle/10665/255884/9789241550062eng.pdf; ;sessionid=EF0468B3482C97E4D3C51A223B5D88E0? sequence=1 (accessed 3 August 2018).

31. Smit M, Olney J, Ford $\mathrm{N}$, et al. The growing burden of noncommunicable disease among persons living with HIV in Zimbabwe. AIDS 2018;32(6):773-782. https://doi.org/10.1097/qad.0000000000001754

32. Haregu T, Oldenburg B, Sestwe G, Elliott J, Nanayakkara V. Epidemiology of comorbidity of HIV/AIDS and non-communicable diseases in developing countries: A systematic review. J Glob Health Care Syst 2012;2(1):1-12.

33. Crothers K, Butt A, Gibert C, et al. Increased COPD among HIV-positive compared to HIV-negative veterans. Chest 2006;130(5):1326-1333. https://doi.org/10.1378/chest.130.5.1326

34. Peck R, Shedafa R, Kalluvya S, et al. Hypertension, kidney disease, HIV and antiretroviral therapy among Tanzanian adults: A cross-sectional study. BMC Med 2014;12:125-135. https://doi.org/10.1186/s12916014-0125-2

35. Johnson L, Mossong J, Dorrington R, et al. Life expectancies of South African adults starting antiretroviral treatment: Collaborative analysis of cohort studies. PLoS Med 2013;10(4):e1001418- e1001428. https:// doi.org/10.1371/journal.pmed.1001418

36. Crum-Cianflone N, Hullsiek K, Marconi V, et al. Trends in the incidence of cancers among HIV-infected persons and the impact of antiretroviral therapy: A 20-year cohort study. AIDS 2009;23(1):41-50. https:// doi.org/10.1097/qad.0b013e328317cc2d

Accepted 13 August 2019. 